\title{
Development of monitoring of water bodies ecological status by the example of small lakes in the North-western Ladoga region
}

\author{
Vasiliy Dmitriev, Svetlana Sedova, Anastasiia Plenkina*, Viktoriia Khomiakova, Diana \\ Avdeevich, Valeriia Ladanova, Andrei Ukis, and Nikolai Paniutin \\ Saint Petersburg State University, 7/9 Universitetskaya nab, 199034, St. Petersburg, Russia
}

\begin{abstract}
By the example of the Suuri Lake $\left(0.37 \mathrm{~km}^{2}\right)$ situated in the North-Western Ladoga region, modern aspects of monitoring the ecological state of water bodies are generalized, including 1) assessment of the rates of mass transfer processes in water ecosystems and the factors affecting them; 2) assessment of the integrated properties of water bodies and their ecosystems based on hierarchical schemes summarizing information about the state of subsystems and their properties in the form of composite indices. The results of the study in 2019 are visualized. Quantitative estimates of the chemical and biological composition and physical properties of the aquatic ecosystem, mass transfer rates, factors influencing them are obtained; the values of the integral indicators for the subsystem and their properties (productivity, water quality, stability) and the integral indicators of the systems and their integrative properties as a whole (ecological status, ecological wellbeing) are estimated. The temporal dynamics of the processes, component composition and complex properties of the aquatic ecosystem are investigated.
\end{abstract}

\section{Introduction}

The subject of the research is new directions and modern accents of monitoring of water bodies ecological state. New monitoring components, which will be discussed in the article, are: 1 - assessment of mass exchange processes rates in water ecosystems and the factors affecting them; 2 - assessment of integrative properties of water bodies and their ecosystems based on hierarchical schemes that summarize information about subsystems state and their properties in composite indices form.

As the result, information is synthesized at separate levels of indicators convolution: 1production properties of waterbody, 2 - quality and toxic contamination of water and sediments, 3 - state of coastal zone, catchment area, and their impact on water body, 4 -

\footnotetext{
* Corresponding author: akuloda@mail.ru
} 
water body stability to changes in regime parameters. The primary purpose of research is to monitor mass transfer processes rates and temporal dynamics of subsystems integrative properties and the system as a whole.

Following developed European Water Framework Directive [1], in the nearest future European Union countries will need to ensure achievement of a high environmental status or environmental wellbeing of all water systems. Because of this, in recent years world and Russian publications have been increasingly focused on development of theoretical and methodological provisions and methods for assessing environmental status and waterbodies environmental wellbeing [2-7].

Russian scientists underline the use of the methods of biological environmental quality control and accounting the impacts of numerous stressors on the ecological state of water bodies using various indices reflecting the state of the subsystems to provide a consolidated assessment of the status of water bodies in traditionally hydrological studies from the perspective of anthropocentrism. Thus, it is possible to take into account climate, anthropogenic and socio-economic changes in scenarios that demonstrate impact of these changes on water quality and the status of water bodies.

\section{Research methods and objects}

Information about the key subject of this study, the Suuri Lake, is shown in Fig. 1. Since the end of the 1980s the monitoring data have been annually collected there. Based on the data from July the characteristics of the lake are the following: the length $1220 \mathrm{~m}$, average width $308.5 \mathrm{~m}$, shoreline length $3.95 \mathrm{~km}$, surface area $376320 \mathrm{~m}^{2}$, maximum depth $6.7 \mathrm{~m}$, average depth $2.9 \mathrm{~m}$, water volume $1092195 \mathrm{~m}^{3}$, thermal content assessed in $1976-10^{5} \mathrm{~J}$.
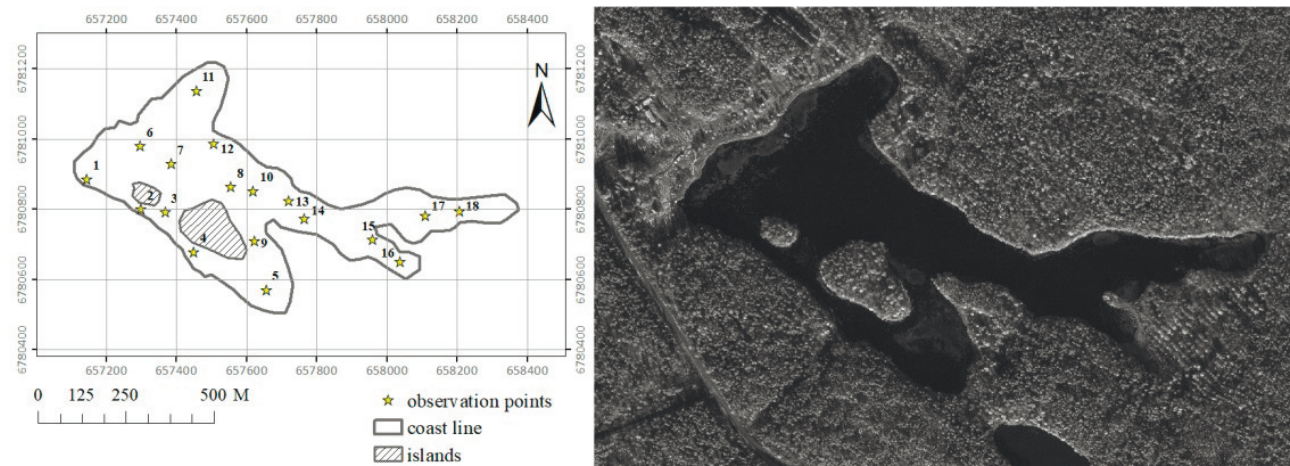

Fig. 1. The Suuri Lake in the North-Western Ladoga region.

The main objective of the research on the Suuri lake was to assess component composition and the rates of organic matte formation and destruction in water ecosystem, estimate the influence of environmental factors on them and their variability; to assess trophic state, water quality and capacity of waterbody biochemical self-purification, as well as some integrative properties of water ecosystem (trophic, quality and toxic water pollution, stability). These tasks were implemented on the basis of traditional methods of environmental monitoring and authors' approaches to study water ecosystems and waterbody ecological state assessment [6]. 


\section{Results and discussion}

Tables 1, 2 and Fig. 2 show some parameters of chemical and biological composition and physical properties of water in the Suuri Lake in July 2019. The number and biomass of phyto-, zooplankton, and zoobenthos was determined. Biological indices of water quality and diversity were calculated. The depth, water temperature, transparency, dissolved oxygen content; electrical conductivity, $\mathrm{pH}$, mineral phosphorus content, and ammonium nitrogen content were observed. The results were visualized in the form of maps and diagrams with isoplets, graphs of vertical distribution, and the tables, examples of which are shown at Fig. 2 and in [6].

In order to study spatial and temporal variability of primary production, chemical composition and lake water physical properties, characteristics were measured at 18 points in mid-July 2019. Measurements were carried out at two horizons: near-surface and nearbottom. In addition, daily observations were made with an interval of 6 hours at point 7 for five horizons: $0,1,2,3$ and $4 \mathrm{~m}$ depth from surface (13.07.2019). Table 1 contains some data averaged by the observational stations (Fig. 2). The transparency of water in lake is low: its average value in the water area was $1.5 \mathrm{~m}$, minimum $-1.28 \mathrm{~m}$, maximum $-1.77 \mathrm{~m}$.

Table 1. Average, maximum and minimum values of some water characteristics in the Suuri Lake.

\begin{tabular}{|l|c|c|c|c|c|c|}
\hline & \multicolumn{3}{|c|}{ Surface } & \multicolumn{3}{c|}{ Bottom } \\
\hline & Average & $\begin{array}{c}\text { Max } \\
(\text { Point \#) }\end{array}$ & $\begin{array}{c}\text { Min } \\
(\text { Point \#) }\end{array}$ & $\begin{array}{c}\text { Average } \\
(\text { Point \#) }\end{array}$ & $\begin{array}{c}\text { Max } \\
\text { (Point \#) }\end{array}$ & $\begin{array}{c}\text { Min } \\
(\text { Point \#) }\end{array}$ \\
\hline $\begin{array}{l}\text { Water } \\
\text { temperature, }{ }^{\circ} \mathrm{C}\end{array}$ & 18.1 & $19.1(13)$ & $17.3(9)$ & 14.3 & $17.9(16)$ & $9.2(8)$ \\
\hline $\mathrm{O}_{2}$ content, mg/1 & 9.46 & $10.34(5)$ & $7.85(6)$ & 6.78 & $8.92(9)$ & $3.1(15)$ \\
\hline $\begin{array}{l}\text { Conductivity, } \\
\mu S / c m\end{array}$ & 104.0 & $105.5(6)$ & $101.7(12)$ & 105.2 & $115.7(14)$ & $101.0(6)$ \\
\hline$p H$ & 6.91 & $7.16(13)$ & $6.68(3)$ & 6.80 & $7.20(18)$ & $6.27(8)$ \\
\hline${\mathrm{P}-\mathrm{PO}_{4}}^{\mathrm{N}-\mathrm{NH}_{4}}$ & 0.048 & $0.080(10)$ & $0.015(9)$ & 0.043 & $0.080(3)$ & $0.025(6)$ \\
\hline
\end{tabular}

Table 2. Heavy metal (mobile form) content (mg/l) in the Suuri lake at station \#7.

\begin{tabular}{|c|c|c|c|c|c|c|c|c|c|}
\hline Horizon, $\mathrm{m}$ & $\mathrm{Fe}$ & $\mathrm{Ni}$ & $\mathrm{Cr}$ & $\mathrm{Pb}$ & $\mathrm{Cd}$ & $\mathrm{Cu}$ & $\mathrm{Zn}$ & $\mathrm{Mn}$ & $\mathrm{Co}$ \\
\hline 0 & 0.00092 & 0.00336 & 0.00137 & \multirow{5}{*}{$<0.0025$} & 0.000025 & \multirow{5}{*}{$<0.0010$} & \multirow{5}{*}{$<0.0025$} & \multirow{4}{*}{$<0.0000040$} & $<0.00009$ \\
\hline 1 & 0.01175 & $<0.00100$ & 0.00491 & & 0.000152 & & & & $<0.00009$ \\
\hline 2 & 0.02430 & 0.00445 & $<0.00100$ & & $<0.000020$ & & & & 0.000093 \\
\hline 3 & 0.00391 & $<0.00100$ & 0.00355 & & $<0.000020$ & & & & $<0.00009$ \\
\hline 4 & 0.00158 & 0.00135 & $<0.00100$ & & 0.000054 & & & 0.0000043 & 0.000108 \\
\hline $\mathrm{MPC}_{\mathrm{s}-\mathrm{g}}$ & 0.3 & 0.1 & 0.5 & 0.03 & 0.001 & 0.25 & 5 & 0.1 & 0.1 \\
\hline $\mathrm{MPC}_{\text {fish }}$ & 0.1 & 0.01 & $\begin{array}{l}0.07 \text { or } \\
0.02 *)\end{array}$ & 0.006 & 0.005 & 0.001 & 0.01 & 0.01 & 0.01 \\
\hline
\end{tabular}

$\mathrm{MPC}_{\mathrm{fish}}-$ maximum permissible concentrations for fishery, $\mathrm{MPC}_{\mathrm{s}-\mathrm{g}}-$ maximum permissible concentrations for sanitary and hygienic purposes. If the element content is less than the sensitivity of device, the values in the Table are shown with the sign " $<" . *) \mathrm{MPC}_{\text {fish }}$ depends on the chromium valence (for trivalent chromium 0.07 , for hexavalent $0.02 \mathrm{mg} / \mathrm{l}$ ).

Phytoplankton, zooplankton and macrozoobenthos studied at the stations of the Suuri Lake in 2019 were represented by taxa which are typical for water bodies [6]. It is shown that planktonic organisms are the inhabitants of relatively clean water (oligo-saprobe and $\beta$ mesosaprobic). The concentration of chlorophyll "a" was determined using experimental approach of V.V. Povazhny (Arctic and Antarctic Research Institute) based on the analysis of light absorption at different wavelengths using the Adobe Photoshop CS6 program. According to this method, average value of chlorophyll "a" in samples was $7.33 \mathrm{mg} / \mathrm{l}$, 
minimum - $4.2 \mathrm{mg} / \mathrm{l}$, maximum $-9.42 \mathrm{mg} / \mathrm{l}$. According to Vinberg scale, the content of chlorophyll "a" in the range of $1-10 \mathrm{mg} / \mathrm{l}$ is typical for mesotrophic water bodies.
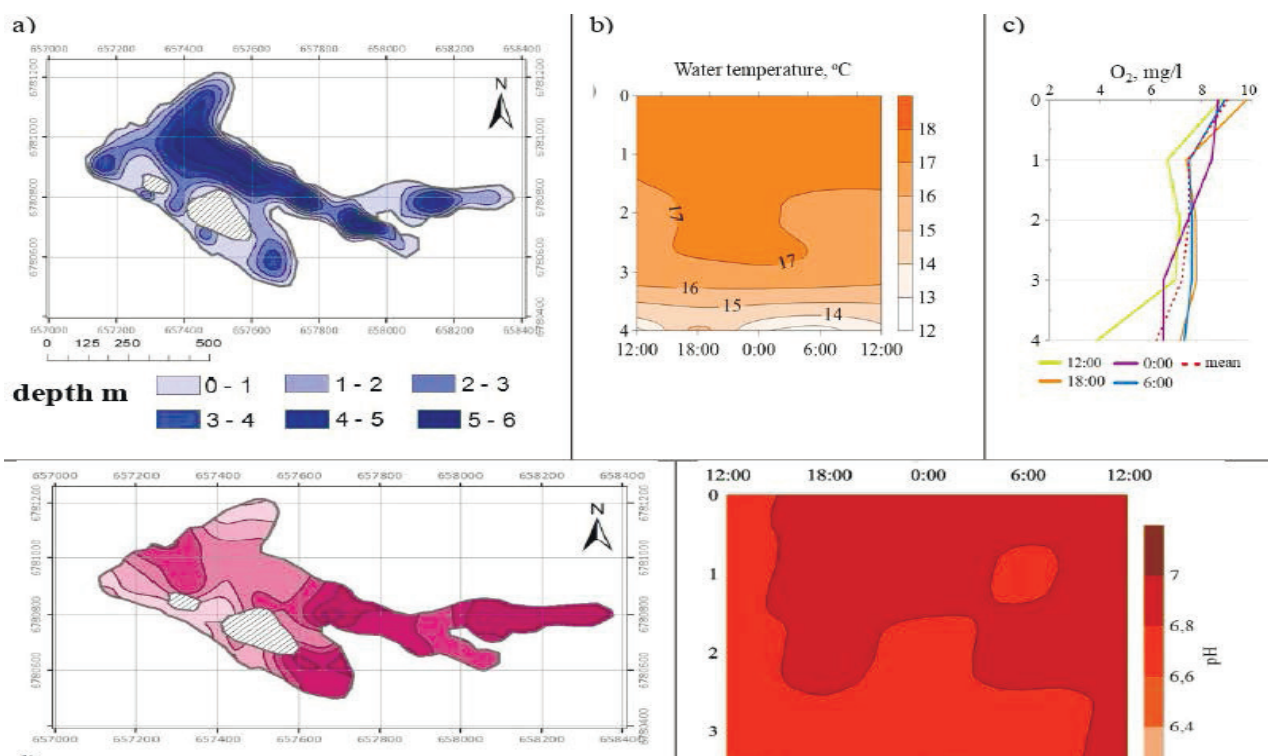

d)
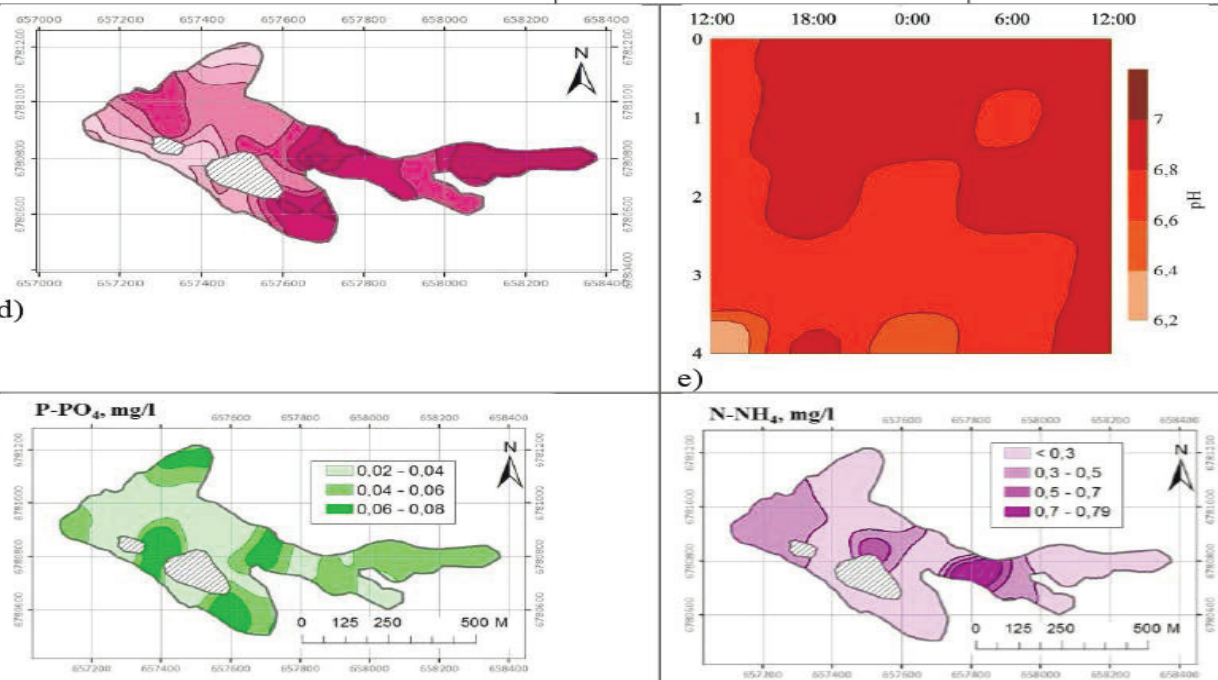

g)

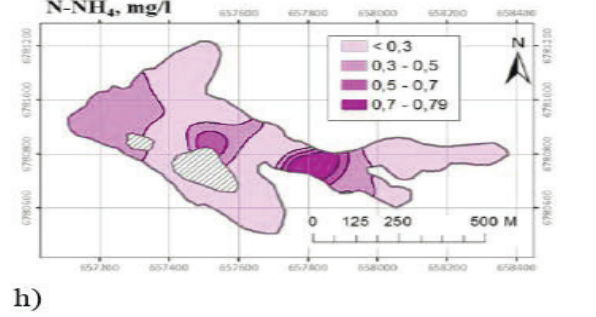

Fig. 2. Spatially-temporary changes of the characteristics in the Suuri Lake in summer 2019: a) map of the Lake depths; b) isoplets of water temperature in the Lake at daily station (station \# 7); c) vertical distribution of oxygen in the water at the daily station (station \# 7); d) spatial distribution of $\mathrm{pH}$ of water on the Lake surface; e) isoplets of water $\mathrm{pH}$ at the daily station (station \# 7); g) spatial distribution of mineral phosphorus on the Lake surface; $h$ ) spatial distribution of ammonium nitrogen on the Lake surface.

In 2019 the total number of zooplankton was equal 103591 ind./1 of which $65.9 \%$ were filterers. Biomass of zooplankton amounted to $966 \mathrm{mg} \mathrm{ww} / \mathrm{m}^{3}$. The filterers biomass share was $85.9 \%$. For two taxa of zooplankton, their indicator saprobiont properties were revealed (the genus Keratella is $\beta$ - mesosaprobic, the genus Trichocerca is oligosaprobic). This allowed attributing the water body to II - III water quality classes. The Shannon taxonomic diversity index for zooplankton was 2.5 and for zoobenthos -2.1 .

The obtained data on zoobenthos were used to calculate the Woodiwiss biotic index (equal to 5, water quality of class III, "moderately polluted"); the BMWP biotic index (Biological Monitoring Working Party), the ASPT index (Average Score Per Taxon). The water quality assessment using updated BMWP index showed that water in the Lake corresponds to "low" class (class IV of 5, class boundaries 16-50). In fact, the result does 
not correspond to real situation in the water body. It is due to the lack of indicator species inhabiting the waters of North-West Russia in the BMWP assessment system.

From the results obtained, it can be seen that trace elements concentration (Table 2) in the Suuri Lake is significantly lower than MPC (both sanitary and fishery, adopted in the Russian Federation). Maximum concentrations of all elements except $\mathrm{Mn}$ are observed at the second horizon and at bottom (for all chemical elements except $\mathrm{Fe}$ and $\mathrm{Cr}$ ).

According to survey of the Suuri Lake on 14.07.2019, a quantitative assessment of factors affecting intensity of aquatic ecosystem pure biosynthesis was carried out. The maximum specific growth rate of phytoplankton is a function of water temperature $f(t)$, which was calculated using Eppley formula (1972) for a mixture of phytoplankton under continuous lighting conditions and Lehman formula (1975) for individual phytoplankton species. The maximum specific growth rate calculated for average water temperature according to Eppley formula was 2.05 , for green plants -4.04 , for diatoms -1.72 . The $f(t)$ values calculated for a mixture of phytoplankton at minimum, average and maximum temperatures vary from 1.95 (for $\mathrm{t}_{\min }=17.3{ }^{\circ} \mathrm{C}$ ) to 2.18 (for $\mathrm{t}_{\max }=19.1{ }^{\circ} \mathrm{C}$ ). At the same time, it was found that green algae are more sensitive to low temperatures, and diatoms are more sensitive to high temperatures.

For describing specific growth rate dependence on illumination $f(I)$, formula of Reiter and J. Steele was used. The inverse function $1 / f(I)$ shows the number of times the lack of light reduces the maximum specific growth rate. The values of minimum, average and maximum water transparency by the $1 / f(I)$ for diatomic phytoplankton vary slightly from 1.61 (for $\mathrm{H}_{\max }=1.8 \mathrm{~m}$ ) to 1.67 (for average $\mathrm{H}=1.5 \mathrm{~m}$ ). As a result, it was found that at an average depth of transparency, lack of light reduces maximum specific growth rate of diatoms by 1.7 times. For green algae, the same trend is observed. The difference between the values of $1 / f(I)$ for various transparency degrees is low. The lack of light in medium transparency layer reduces green growth rate by 1.4 times. The calculated data on temperature influence and light were confirmed by the observations in the Lake. In July, green algae had an advantage in development compared to diatomic phytoplankton.

The estimation of biogenic restriction of primary production in the Lake was carried out using Michaelis-Menten-Mono model based on hydrochemical observations of ammonium nitrogen and mineral phosphorus content. For this purpose, parameters $r_{P}$ and $r_{P}$ were calculated, showing how many times the lack of nitrogen or phosphorus reduces maximum possible intensity of organic matter production by phytoplankton. Average concentration of mineral phosphorus and ammonium nitrogen in surface layer was $0.048 \mathrm{mgP} / 1$ and 0.15 $\mathrm{mgN} / 1$. Over entire area of the lake, phosphorus limits production by 1.42 , and nitrogen by 1.23 times. The main biogenic element that limits primary production in the Suri Lake is phosphorus. Similar trend was observed in July 2016-2018 [6].

The results of a multi-factor experiment by T. V. Zamaraeva and A. A. Rudkova (1987) [9] and the observations at the Suuri lake (28.06.2019) were used to assess the influence of heavy metals (lead and cadmium) on planktonic algae growth. According to the calculations results, maximum specific growth rate of phytoplankton in the Suuri Lake in June-July, assuming linear nature of relationship reflecting the influence of $\mathrm{Cd}$ and $\mathrm{Pb}$ on growth, decreases by 1.65 times. The lake ecosystem is more affected by cadmium (the planktonic algae growth rate is reduced by 1.47 times).

To assess the combined effect of all factors on organic matter production by phytoplankton, the Mitcherlich model and the Liebig model were used. The results show that the models reflect the effect of the combined action of factors in different ways. The M-model reduces the factors effect more than the L-model. The use of M- or L-models for factor accounting in environmental models requires further experimental verification.

Production-destruction relations in the Suuri Lake were studied on July 13-16, 2019 at station 7. An oxygen modification of flask method was used (exposure 1 day). With an 
average transparency depth of $1.50 \mathrm{~m}$, average values of $\mathrm{P}_{\text {gross }}=1.13 \mathrm{mg} \mathrm{O} / 1$ *day and $\mathrm{D}=$ $2.30 \mathrm{mg} \mathrm{O} / 1^{*}$ day.

According to the calculations for one day (July 13-14, 2019), $44.89 \mathrm{kgC} /$ day was synthesized at the depth of average water transparency. During the same period, 272.53 $\mathrm{kgC} /$ day of organic matter was destroyed.

The experiment to measure oxygen content in water was performed on July 11-12, 2019 with an optical sensor (Optod PreSens Fibox4). The results of production studies using this method with an exposure of 1 hour gave average values of $\mathrm{P}_{\text {gross }}=0.49 \mathrm{mg} \mathrm{O} / 1 * \mathrm{~h}, \mathrm{P}_{\text {net }}=$ $0.42 \mathrm{mg} \mathrm{O}_{2} / 1 * \mathrm{~h}, \mathrm{D}=0.09 \mathrm{mg} \mathrm{O} \mathrm{O}_{2} / 1 * \mathrm{~h}$. By this technique the calculation formulas were proposed for estimation of $\mathrm{P}_{\text {gross }}, \mathrm{P}_{\text {net }}$ and $\mathrm{D}$.

The assessment of the Suuri Lake trophic status in 2019 was performed on the basis of component-by-component analysis and integral estimation using composite index method. For the first approach, 10 characteristics were selected. According to this assessment, trophic status of the Lake corresponds to oligotrophic class by 3 parameters, mesotrophic class by 5 parameters, and eutrophication class by 2 parameters. The results of trophic status integral assessment showed that the Suuri Lake belongs to mesotrophic class left border. The conclusions on the trophic status assessment of the Lake conducted in previous years were analyzed. From them it follows that the first method produced similar results, and the second method referred the Lake to the middle range of mesotrophic class.

The degree of water ecosystem self-purification of the Suuri Lake was estimated based on the ratio of destruction to gross primary production $\left(D / \mathrm{P}_{\text {gross }}\right)$ and the time of water clarification by zooplankters-filters ( $\mathrm{T}$, day). The value of $D / \mathrm{P}_{\text {gross }}$ in the first observations series (13-14.07) was lower than 1, which indicated in favor of organic matter formation in the Lake. During this period, the formation of $\mathrm{P}_{\text {net }}=0.28 \mathrm{mg} \mathrm{O}_{2} / 1 *$ day was recorded. During the Lake survey in central part (14-16.07), the destruction processes exceeded its new formation. The average $D / \mathrm{P}_{\text {gross }}$ value was 3.02 . These data show that the system is capable of self-cleaning and copes with the loads on it [6].

The time of water clarification by zooplankters-filters $(\mathrm{T})$ was estimated for maximum, average and minimum water temperature. $\mathrm{T}$ varied between 5.4 and 6.3 days, which is more than $\mathrm{T}$ at this time in 2018 (1.2 - 1.5 days).

The water quality assessment in the Lake was performed based on hydrochemical and hydrobiological data: 1 - on a component-by-component approach (10 parameters); 2 using the elaboration of composite indices accounting for hydrophysical, hydrochemical and hydrobiological data and 8 microelements content in the water. For the first approach, the spread of classes was from I to V. For the second approach, the surface water of the Suuri Lake is assigned to II class of water quality (integral indicator of quality, IIQ $=0.17$ ), closer to the right border (the range of variation of IPI in this class is $0.08-0.19$ ).

The assessment of the stability of the Suuri lake to changes in natural parameters (potential stability) and anthropogenic regimes was based on point-index method and several composite indices $[6,7]$. According to the first method, the sum of the stability points amounted to 22. It allowed attributing potential stability as being at classes III and IV border (i.e., the stability is below average). The same conclusions were obtained in 2017-2018. Composite stability indices were calculated for two types ( 1 - adaptive, 2 regenerative) [7]. In all cases, the lake potential stability was rated by class III.

In [7], we performed an integral assessment of ecological status composite index of water body using the observations from recent years, such as trophic status, water quality and sustainability data. The results show that the integrated indicator of environmental status (IIES) has decreased by $10 \%$ over the past three years. During these years, the lake was able to maintain its ecological status (class III, closer to left border). It was found that at identified rate of changes of IIES, the lake will move to IV, lower ecological status class in about 5 years. 
Attributes and methods of assessing ecological well-being of water ecosystem have been developed, and the models of ecological well-being (WB) classification have been formulated $[6,8]$. An integral estimation of WB is performed for the Suuri Lake. For recent years, the Lake's WB is rated by class II (above average). At the same time, integral WB indicator values changed within the II class (closer to the right border), and in some years fell into the left border of III class.

\section{Conclusions}

On the example of key water body, new directions and modern accents of monitoring water bodies ecological state are summarized. The focus: 1-assessment of mass exchange processes speed in water ecosystems and factors affecting them; 2-assessment of water bodies integrative properties and their ecosystems based on hierarchical schemes that generalize information about the subsystems state and their properties in composite indexes form. Quantitative estimates of mass transfer rates, factors affecting them, and integral indicators values for subsystems (productivity, water quality, stability) and systems (ecological status, environmental well-being) for a small lake in the North-Western Ladoga region were obtained.

This research was conducted with the support from Russian Foundation for Basic Research, project №19-05-00683 A.

\section{References}

1. Directive 2000/60/EC of the European Parliament and of the Council of 23 October 2000 establishing a framework for Community action in the field of water policy. Official Journal L 327, 22/12/2000, 0001 - 0073 (2000).

2. E. Molina-Navarro, P. Segurado, P. Branco, C. Almeida, H. E. Andersen. Predicting the ecological status of rivers and streams under different climatic and socioeconomic scenarios using Bayesian Belief Networks. Limnologica. 80. 125742 (2019) 10.1016/j.limno.2019.125742

3. B. Grizzetti, A. Pistocchi, C. Liquete, A. Udias, F. Bouraoui, W. van de Bund Sci. Rep. 7, 205 (2017)

4. T. Erös, W. H. Lowe Current Landscape Ecology Reports, 4, 103-112 (2019)

5. S.A. Ostroumov Rus. J. Gen. Chem., 80 (13): 2754-2761 (2010)

6. S.A. Sedova, V.V. Dmitriev, A. A. Chetverova Certificate of state registration of database No. 2019621679 "Database for identifying the ecological status and factors of mass transfer in the aquatic ecosystem using the example of Lake Suuri (LAKESUURI-ECOSYSTEM). Date of registration: 09/26/2019 (2019) (in Russian).

7. S.A. Sedova, V.V. Dmitriev European Journal of Natural History, 1, 37-44 (2020) (in Russian).

8. V. V. Dmitriev, V. V. Terleev, A. O. Nikonorov, A. N. Ogurtsov, A. G. Osipov, Y. N. Sergeyev, V. P. Kulesh, I. V. Fedorova. Landscape Modelling and Decision Support, 231-253 (2020)

9. T. V. Zamaraeva, A. A. Rudkova Studying the dependence of the growth rate of unicellular algae on temperature, acidity and concentration of heavy metals // Problems of environmental monitoring and modeling of ecosystems. T. 12. (1989) (in Russia). 